\title{
Tracking Mediator Behaviour: An Initial Investigation
}

\author{
Virginia Phillips*
}

Mediation is perhaps the most often used and least easily understood dispute resolution procedure in the field of industrial relations. It has played a particularly prominent role in industrial relations in New Zealand, having a long history at the centre of both wage negotiation or interest disputes, and personal and contractual rights disputes. It retains a central role in the resolution of personal grievances, contract interpretation disputes, wage arrears and other disputes of rights in the Employment Tribunal under the Employment Contracts Act 1991.

Recently, papers by experienced New Zealand mediators have drawn on anecdotal data in providing valuable insights into dispute resolution in the Tribunal (Gardiner 1994; Grills 1992, 1993). However, research on industrial mediation in New Zealand is sparse, essentially limited to the work of Howells and Cathro $(1977,1986)$ and Miller (1983).

Overseas research on mediation is more plentiful. A major focus of the overseas research has been mediator behaviour. One theme of this behavioral approach has been to examine the links between characteristics of the dispute, or of the disputants, and the mediator's choice of mediation tactics in attempting to resolve the dispute. The pilot research project which this research note reports begins an examination of these links in a contempory New Zealand setting. The purposes of the note are to report the methodology developed for this initial experimental research into mediator behaviour, and to give an indication of preliminary findings from the pilot study.

\section{The theoretical framework}

It is possible to identify in the overseas literature a number of broad strategies around which mediation revolves. In an exploratory study, Kressel proposed (1972) a categorization for general mediation strategies. This categorization takes a sequential view of mediation, implying that three sets of strategies will parallel the sequential stages of dispute resolution. The underlying assumption is that the choice of tactics is related to the different points in the negotiation process, and to the general strategies appropriate to those points. Subsequently updated by Kressel and Pruitt (1985), Kressel's categorization is extensively 
used in mediation research (Carnevale \& Pegnetter 1985; Lim \& Carnevale 1990; McLaughlin, Lim \& Carnevale 1991). Its fundamental nature has been accepted by many researchers as a convenient summary of the types of tactics that might be expected to be employed by mediators during the different stages of mediation (Kochan \& Jick 1978; Gerhart \& Drotning 1980; Howells \& Cathro 1986).

For an observational study, the Kressel \& Pruitt (1985) scheme provided an effective framework for the investigation of the tactical choices of mediators in relation to selected dispute and disputant characteristics. This scheme was adopted for the research reported in this note with slight modification for the shift in focus to grievance mediation, as opposed to 'interest' mediation.

In the Kressel and Pruitt model:

Reflexive tactics are those interventions used by mediators to orient themselves to the dispute and to establish the groundwork upon which later activity will be built.

Contextual tactics are those used by the mediator to alter the climate of the mediation so as to enable the parties to reach agreement with minimal intervention by the mediator.

Substantive tactics include the active promotion of specific solutions or attempts at pressing, or manipulating the parties to 'closer' positions.

Specific tactics illustrative of each category are listed in the appendix to this note.

A range of dispute and disputant characteristics have been tested in overseas research as determinants of mediator choice of tactics. Drawing on this literature for the present study, the following factors were hypothesized as likely to influence mediators in their choice of tactics:

Personal hostility between the disputants (following Kochan \& Jick 1978; Karim \& Stone 1986; Kochan \& Baderschneider 1978; Gerhart \& Drotning 1980; Rubin 1980; Lim \& Carnevale 1990)

The incompatibility of the disputants' priorities as to remedies (following Gerhart \& Drotning 1980; Simkin 1971; Carnevale \& Pegnetter 1985)

The amount of advocacy experience the disputants' advocates have (following Druckman 1971; Kochan \& Jick 1978; Kochan \& Baderschneider 1978; Carnevale \& Pegnetter 1985; Karim \& Stone 1986)

Specifically, the hypotheses formulated for testing in the pilot research were as follows:

Hypothesis 1: The greater the personal hostility between the disputants, the greater the likelihood that the mediator will employ substantive tactics; 
Hypothesis 2: The greater the incompatibility between the remedy priorities of the disputants, the greater the likelihood that the mediator will employ substantive tactics;

Hypothesis 3: The higher the priority attached by the applicant to reinstatement as a remedy, the greater the likelihood that the mediator will employ substantive tactics;

Hypothesis 4: The less experienced the advocates, the greater the likelihood that the mediator will employ contextual tactics.

As a general rule, the mediators used reflexive tactics early in the process to identify levels of hostility, remedy compatibility and advocate experience.

\section{Research methodology}

In the pilot study reported here, data was gathered by observing two experienced Employment Tribunal mediators during the mediation of a total of 14 personal grievances. All cases alleged unjustified dismissal. The mediators' use of a particular strategy reflexive, contextual or substantive - was measured by the amount of time spent using tactics categorized as belonging to that particular strategy. The data was recorded in 5 minute increments on a measurement table. The time recording of the process was initiated when the mediator first introduced both himself and the observer to one of the parties. Prior to this initial introduction, the mediator would ask permission from the parties for the observer to be present during the proceedings, giving a brief explanation of the research.

The time period during which the mediator used a particular tactic was observed and noted. Quantifying the exact amount of time for which a specific tactic was used, was sometimes difficult. The mediator's intervening actions ranged from a single comment that might occupy only seconds, to a "lecture" or extended line of inquiry occupying several or many minutes. The data which resulted from observing the mediators in action were a series of entries on a tactical time sheet representing the visible deployment of specific tactics over specific time frames.

After the conclusion of each mediation, a limited amount of time was available for a review of the case with the mediator. This time was used to assist the researcher to classify the dispute and disputants characteristics and to discuss events that had transpired during the mediation process. The first page of the measurement instrument detailed the dispute or disputant variables of hostility, remedy compatibility, remedy priority, and the level of advocate experience. The ratings for these variables were later developed into a case profile allowing for the classification of the dispute based on its characteristics. As the mediation proceeded, notes were taken to capture the general conversational detail and case atmosphere. For each case the tactical behaviour of the mediator was graphed to illustrate the number of times each tactic was used in the mediation, the number of times each category of tactic was used, and the categories of tactics as a function of time. Similar cases were compared and analyzed. The tactical data was then collated for all the cases and the 
two mediators compared with respect to the time length of mediations, dispute and disputant characteristics, and use of tactics.

\section{Research findings}

In large measure because of the small sample size for the pilot study, the substantive findings are more suggestive than conclusive. They do, however, provide sufficient endorsement of the methodology to encourage further research into mediator behaviour. The findings are set out below.

\section{Individual mediation styles}

To examine the impact of the mediators' personal styles, the cases mediated by Mediator A and Mediator B were compared. Mediator A was, in general, more tactically active, using a wider range of tactics more frequently than Mediator B. He also spent a longer average period of time in mediation. Mediator A had a greater tendency than B to use contextual tactics. With only one exception, cases with a high use of contextual tactics were mediated by Mediator A. Mediator B mediated most of the cases for which the use of substantive tactics was greatest. The distinct styles of Mediators A and B are apparent in Graph 1.

Graph 1: The average numbers of uses of different types of tactics: a comparison between the mediators

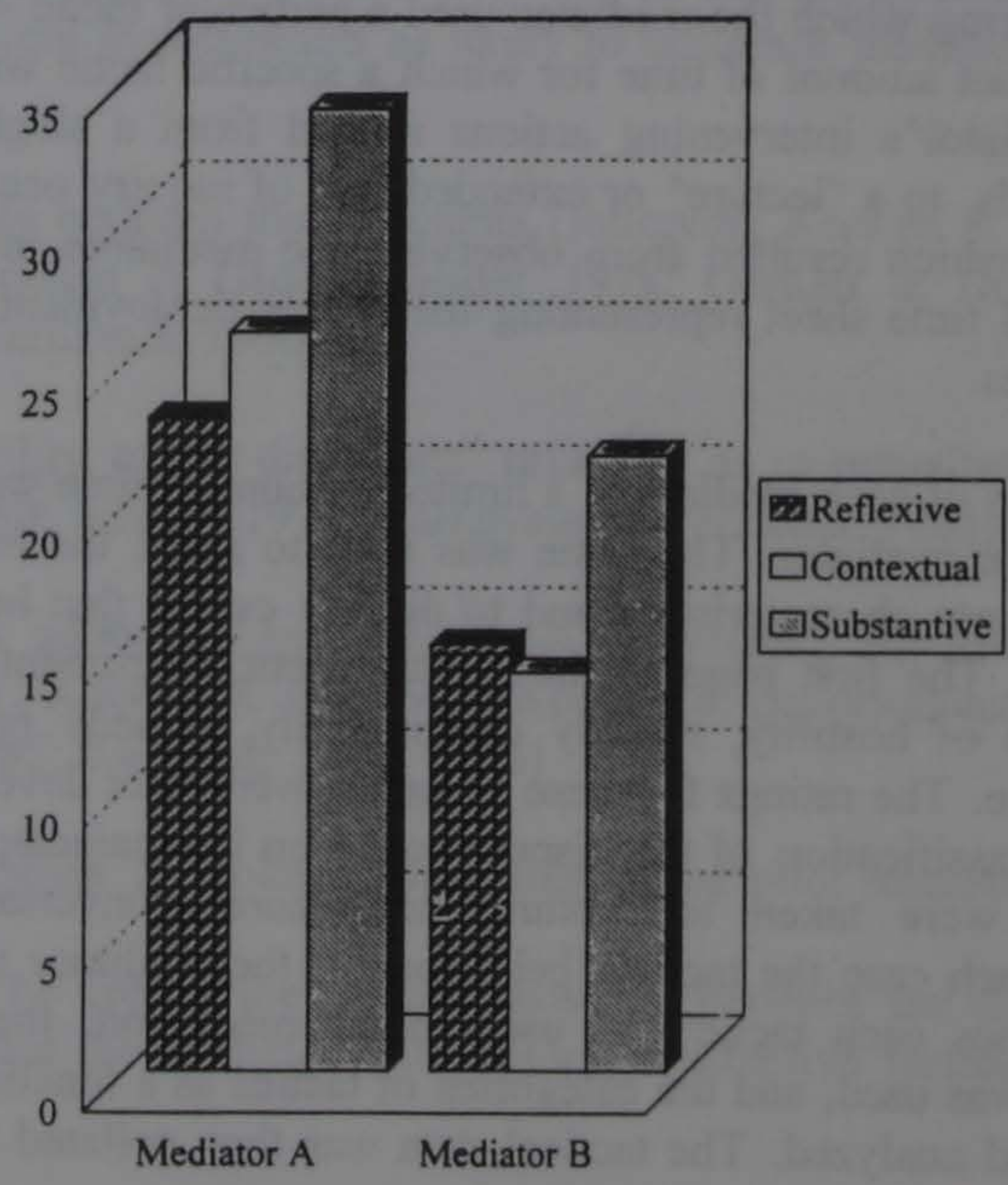


What the graph suggests is that Mediator A tends to spend the time to run through the full repertoire of tactics guiding the parties to a settlement, while Mediator B tends to concentrate the process more with an earlier resort to substantive tactics and a heavier use of substantive tactics relative to reflexive or contextual tactics. In essence, Mediator B assesses the settlement potential of each case quite early on, and either presses early and hard for settlement where settlement prospects are good, or discontinues the process where settlement is considered unlikely.

\section{Hostility}

There was little hostility apparent in the 14 mediations observed. Most disputant parties were tolerant of one another. Three cases with shades of hostility are worth mentioning. Due to the personalities and the alleged sexual harassment nature of the grievance, Case 2 was a potentially volatile dispute. The strategy employed by the mediator was to keep the parties separated from the outset with resolution being achieved without the parties ever coming in direct contact. Cases 11 and 14 were classified as unfriendly. Tension, anger, frustration, ill-feeling and a lack of trust were noticeable, intermittently, between the parties in both verbal and body language. Both cases involved a high level of substantive tactics and while this might offer support for the hypothesis that mediators will respond to hostility with an increased use of substantive tactics, no real conclusions can be made. The research cases did not involve a sufficiently high level of hostility to comment with confidence about the relationship suggested in Hypothesis 1 between the mediator's use of substantive tactics and the level of dispute hostility. The advocates served to filter the emotions of the disputants during the hearings, while the mediator seemed to make comment where necessary about the tone of the discussion between the parties, thereby preempting any overt hostility.

\section{Remedy incompatibility}

Of the fourteen cases, seven grievances were considered to have high remedy incompatibility. Of these seven cases only one was resolved at mediation. Five of these cases were expected by the mediator to go on to adjudication, with one case expected to settle post-mediation but prior to adjudication. Of the seven cases judged to be essentially compatible as to remedies, six were resolved in mediation. The only unsettled case involved the simultaneous mediation of two related personal grievances.

Graph 2 ranks cases by the number of substantive tactics used. As is apparent in the graph, the number varies widely across the cases. 


\section{Graph 2: The number of substantive tactics used}

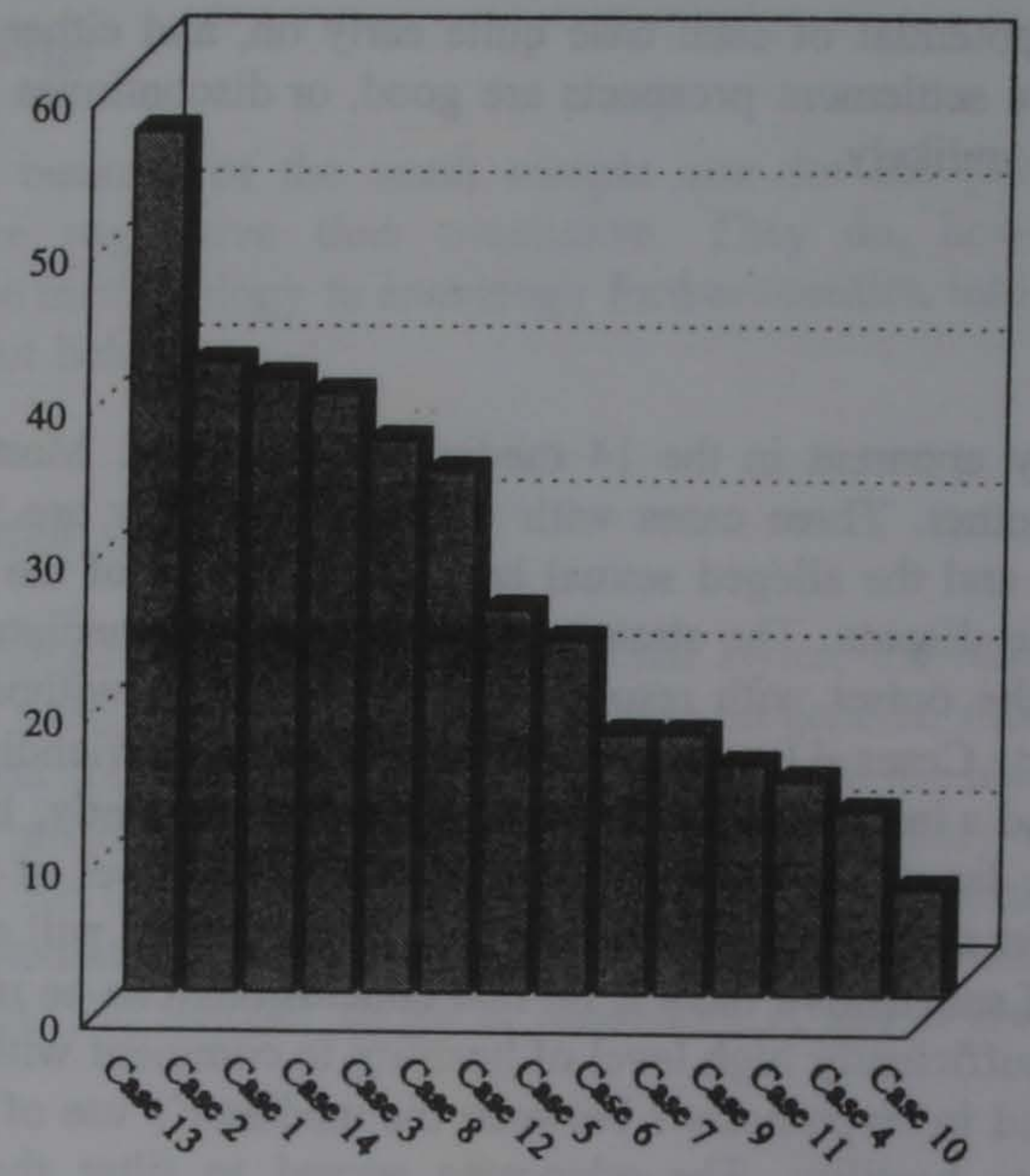

Medietion ceses

Hypothesis 2 suggested that substantive tactics would be used to a greater extent in cases where remedy positions were seen as more incompatible. Unexpectedly, the use of substantive tactics was higher in those disputes where the positions of the parties on remedies were 'essentially compatible'. This would seem to suggest that mediators may employ substantive tactics, essentially pushing for settlement for a time, in all disputes, but that they discontinue or decrease their use of substantive tactics when it becomes apparent to them that the parties are not prepared to settle. Alternatively if it appears that the parties may settle they continue to push with substantive tactics until settlement is achieved.

\section{Priority attached to reinstatement}

Reinstatement as a remedy was claimed in only five of the fourteen cases observed for the study. In three of these cases, it was the view of the mediator that the claim for reinstatement was tactical rather than real. For the two cases where reinstatement was seriously sought, Cases 5 and 10, substantive tactics were not extensively used by the mediator. Both cases were short in duration. In each case it was apparent to the mediator early on that the positions on remedies including reinstatement were incompatible and that the case was unlikely to settle. Having made this assessment, in neither case did the mediator push the parties very far or for long. 
No real support was found for Hypothesis 3. Because of subsample size, it was not possible to draw conclusions about the impact of reinstatement as a claimed remedy on mediator tactics. What does seem to be the case is that a claim for reinstatement contributes to the likelihood of remedy incompatibility.

\section{The level of advocate experience}

There was a wide variety of advocates representing the parties in the mediations observed. There were a total of 26 advocates across the 14 personal grievances, including three parties who represented themselves. Of the 23 professional advocates, four were lawyers, four were company staff advocates, three were Employer Association advocates, three were union officials and the remaining 10 were industrial relations consultants. Those in the last category was about evenly split between the representation of applicants and respondents.

Mediation experience varied, with the majority of those appearing being classified as highly experienced, having participated in ten or more mediations. Eight of the advocates had been to mediation less than five times, with four out of the eight being in mediation for the first time. It was hypothesized that contextual tactics would be used to a greater extent in cases involving less experienced advocates. Graph 3 ranks cases by the number of contextual tactics used. Again it is apparent that the use of contextual tactics varied widely across the cases.

\section{Graph 3: The number of contertual tactics used}

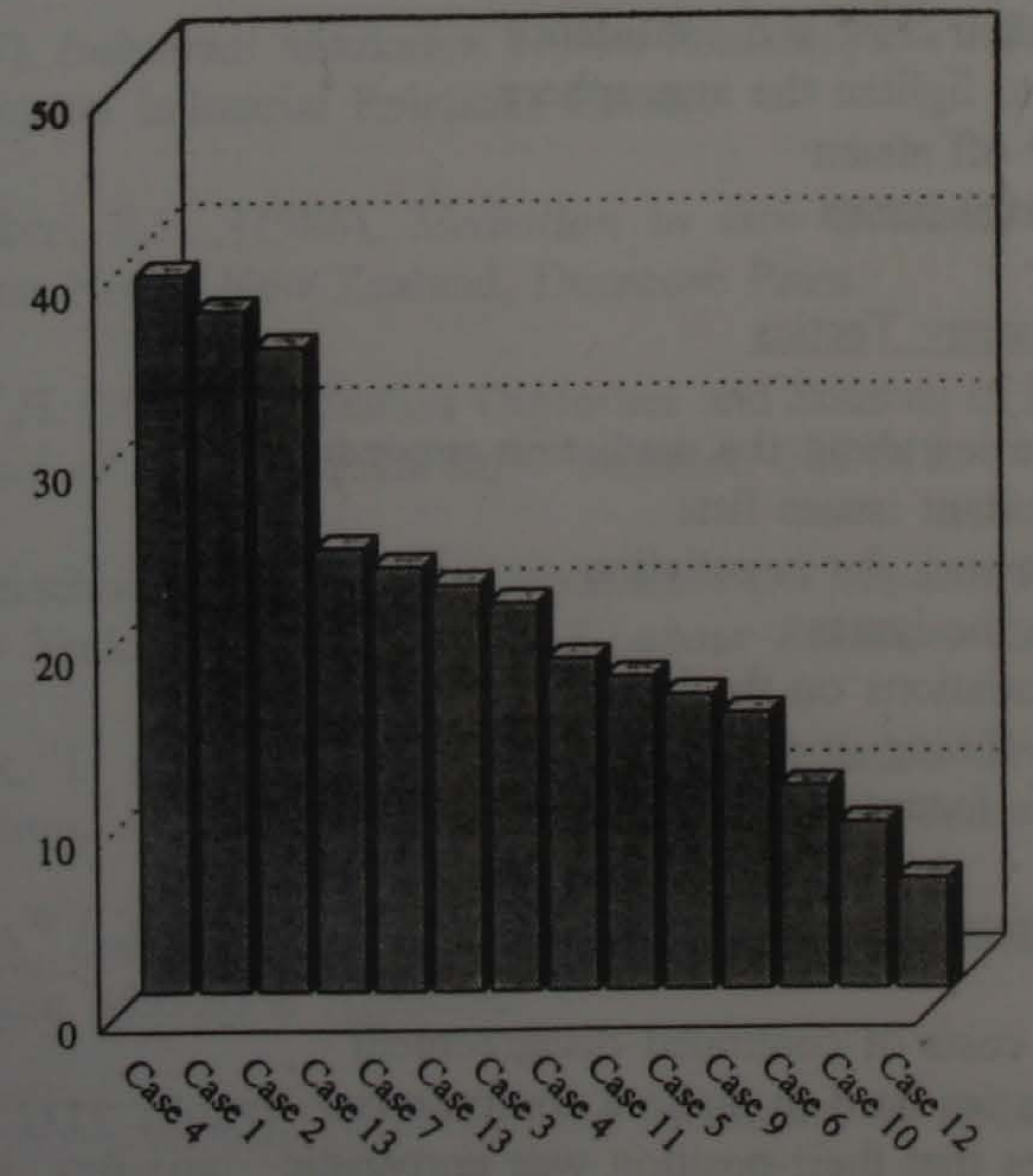

Mediation cases 
There is some support for Hypothesis 4. The mediations that involved at least one inexperienced advocate (Cases 1, 2, 7, 8, 11, 12,13) were, with the exception of Case 12, characterised by high or fairly high use of contextual tactics. This provides some tentative support for the hypothesis that mediators tailor their use of contextual tactics to the level of perceived advocacy experience. Cases where the use of contextual tactics was highest relative to the use of substantive tactics all involved at least one inexperienced advocate.

\section{Concluding comment}

Grievance mediation in New Zealand deserves attention from researchers given that it has long been a principal method for the resolution of industrial relations conflict in this country, and given recent attention to grievance mediation and alternative dispute resolution more widely overseas. While the findings reported here from the exploratory study fall well short of being conclusive, they do provide encouragement and avenues for further research. Certainly, an expanded replication of the pilot study should allow the drawing of more confident conclusions that contribute to a better understanding of the sometimes mysterious process of mediation.

\section{Appendix}

\section{$\underline{\text { Reflexive Strategy Tactics }}$}

Developed a rapport with the parties

Avoided taking sides on important issues

Tried to gain their trust and confidence

Used humour to lighten the atmosphere

Let them blow off steam

Identified the real issues

\section{Contextual Strategy Tactics}

Educate the parties about the mediation procedure

Settle the important issues first

Devise a framework for negotiation

Help prioritize the issues

Focus the negotiations on the issues

Controlled the timing or pace of negotiations

Kept the paries focused on the impasse issues

\section{$\underline{\text { Substantive Strategy Tactics }}$}

Discussed the costs of continued disagreement Pressed the parties hard to make a compromise Told the parties that their position was unrealistic Expressed displeasure at the progress

Tried to change the expectations of the parties 
Used late hours, long mediation to facilitate compromise

Argued their case to the other party

Discussed case strengths and weaknesses

Made substantive suggestions for settlement

\section{References}

Carnevale, P.J., Pegnetter, R. (1985), The Selection of Mediation Tactics in Public Sector Disputes: A Contingency Approach, Journal of Social Issues, 41(2): 65-81.

Druckman, D. (1971), The Influence of the Situation on the Interparty Conflict, Journal of Conflict Resolution, vol.XV,4, 523-555.

Gardiner, R. (1994), Personal Grievance Mediation in the Employment Tribunal, New Zealand Journal of Industrial Relations, 18(3): 342-351.

Gerhart, P.F., Drotning, J.E. (1980), Dispute Settlement and the Intensity of Mediation, Industrial Relations, 19(3) Fall: 352-359.

Grills, W. (1992), Practitioner Paper: Dispute Resolution in the Employment Tribunal: Mediation, New Zealand Journal of Industrial Relations, 17(3): 333-346.

Grills, W. (1993), Practitioner Paper: Dispute Resolution in the Employment Tribunal Part Two: Adjudication, New Zealand Journal of Industrial Relations, 18(1), 84-93.

Howells, J.M. (1977), Industrial Mediation in New Zealand: The First Two Years, Victoria University of Wellington Industrial Relations Centre.

Howells, J.M., Cathro, S.H. (1986), Mediation in New Zealand: The Attitudes of the Mediated, Palmerston North, New Zealand, Dunmore Press.

Karim, A., Stone, T.H. (1986), Mediation Outcomes and Sources of Impasse: An Empirical Investigation, Journal of Labour Research, 7 Summer: 309-318.

Kochan, T.A., Baderschneider, J. (1978), Dependence on Impasse Procedures: Police and Firefighters in New York State, Industrial and Labour Relations Review, 31(4): 431-449.

Kochan, T.A., Jick, T. (1978), The Public Sector Mediation Process: A Theory and Empirical Examination, Journal of Conflict Resolution, 22(2) June: 209-240.

Kressel, K. (1972), Labour Mediation: An Exploratory Survey, Albany New York Association of Labour Mediation Agencies.

Kressel, K., Pruitt, D.G. (1985), Themes in the Mediation of Social Conflict, Journal of Social Issues, 41(2): 179-198. 
Lim, R.G., Carnevale, P.J. (1992), Contingencies in the Mediation of Disputes, Journal of Personality and Social Psychology, 58(2): 259-272.

Miller, R.L. (1983), The Resolution of Dispute and Grievances in New Zealand: Analysis, Observations and Recommendations, Industrial Relations Research Monograph No.8, Victoria University of Wellington.

McLaughlin, M.E., Carnevale, P.J., Lim, R.G. (1991), Professional Mediators' Judgements of Mediation Tactics; Multidimensional Scaling and Cluster Analyses, Journal of Applied Psychology, 76(3): 465-472.

Simkin, W.E. (1971), Mediation and the Dynamics of Collective Bargaining, Washington D.C., The Bureau of National Affairs Inc.

Rubin, J.Z. (1980), Experimental Research on Third Party Intervention in Conflict: Toward Some Generalisations. Psychology Bulletin, 87(2): 379-391. 